\title{
Sciatica and Incomplete Paraplegia After Spontaneous Haematoma of the Spinal Cord Due to a Cumarine - Induced Coagulopathy: Case Report
}

\author{
Juraj Artner ${ }^{*}, 1$, F. Leucht ${ }^{1}$, C. Schulz ${ }^{2}$ and B. Cakir ${ }^{1}$ \\ ${ }^{I}$ Department of Orthopaedic Surgery, University of Ulm, RKU Ulm, Germany \\ ${ }^{2}$ Department of Neurosurgery, Military Hospital, Ulm, Germany
}

\begin{abstract}
Spontaneous spinal haematoma is a rare cause of sciatica. We present a case of a 73 year old patient, who was admitted to our department and suffered from spontaneous sciatica over 24 hours. During the examination, the patient presented undulating symptoms of paraplegia, varying from incomplete loss of power in the left lower limb to complete plegia. The patient presented multiple diseases like biological aortic valve replacement, diabetes, hypertonia in her medical history, etc. Due to an additional absolute arrhythmia she ingested a cumarine medication. The tomographic imaging revealed a spontaneous lumbar and cranial subarachnoidal haematoma.
\end{abstract}

Keywords: Spinal haematoma, sciatica, cumarine, subarachnoidal hemorrhage, vasospasm, paraplegia.

\section{CASE REPORT}

The 73 year old female patient was admitted to our orthopaedic department on the basis of intermittent pain in her left lower limb. She reported of gait disturbance, weakness and recurring sciatica in the left lower limb since about 24 hours. At the time of her hospitalisation, she wasn 't able to walk anymore.

\section{HISTORY}

Intermittent pain in the left leg with incomplete paresis and paresthesia since 24 hours. The onset of symptoms was spontaneous; there was no history of trauma. No history of lumbago, no fever or weight loss. The symptoms were reported for the first time. The current medication comprised antihypertensive drugs, diuretics and an anticoagulans (cumarine). The patient reported a biologic aortal valve implantation from 6 months ago and an atrial fibrillation as a reason for the anticoagulation.

\section{EXAMINATION}

On physical examination, we had an adipose female patient with a height of $165 \mathrm{~cm}$ and weight of $95 \mathrm{~kg}$ (BMI= 34.9). The mental status was normal. During the examination, the patient was asked to stand up for the purpose of inspection. While trying to get into a prone position, the patient lost control of her left lower limb. At this moment she also suffered urine incontinence the first time. Further examination presented an incomplete paraplegia of the lower limb, while the right limb had a normal motor and sensible function. On the left side, there was a loss of power for the hip flexion, knee extension and foot elevation, varying from 4/5 MRC (medical research council) grade to full plegia (Asia Impairment Scale AIS D

*Address correspondence to this author at the Department of Orthopaedic Surgery, University of Ulm, RKU, Oberer Eselsberg 45, $89081 \mathrm{Ulm}$, Germany; Tel: 0049-731-177-5111; Fax: 0049-731-177-1058;

E-mail: j.artner@gmail.com to AIS C) and inability to move the limb during a second examination, which was performed 15 minutes later in the radiology department by the same examiner. Lasègue and Bragard sign was positive on the left side. Babinski sign was bilaterally negative. There was no saddle block anaesthesia present and the anal sphincter tonus was normal. Peripheral pulse status was also normal. Crural varicosis was inspected, but there was no change in limb circumference, color, temperature, pain on palpation of the calves nor near the great saphenous vein.

There was no tenderness on the examination of the spine. Abdomen was smooth and also presented no tenderness to palpation.

During the radiographic examination (changing position), the patient presented a rapid worsening of the paresis, not being able to move the affected limb. Because of undulating neurologic deficits in the lower limb, the patient was admitted to cranial computer tomography and magnetic resonance tomography examination of the spine.

\section{LABORATORY FINDINGS}

Severe coagulopathy with Quick of 11\% (Reference range $>70 \%$ ), INR 5.10 (Reference range 2.0-4.5), PTT 62.2 sec (Reference range 22.3-31.7 sec) and fibrinogen of 5.53 $\mathrm{g} / 1$ (2.5-4.5 g/l), corresponding to changes due to current cumarine medication. White blood cell count was raised to $14.0 \mathrm{G} / \mathrm{l}$, C- reactive peptide to $23.47 \mathrm{mg} / 1$ (Reference range $<5.0 \mathrm{mg} / \mathrm{l})$. Other parameters were within normal values.

\section{IMAGING}

The conventional radiography of the spine was performed in horizontal posture because of the patient's inability to stand. Fractures, neoplastic formation and instability were excluded. Cranial computed-tomography presented a diffuse subarachnoidal haematoma (see Fig. 3) but not predominantly in the basal cisterns (basal pentagon). The magnetic resonance tomography imaging showed a spontaneous intradural haematoma at the level of the $12^{\text {th }}$ thoracic and $1^{\text {st }}$ lumbar vertebra and a surrounding edema of 
the myelon, extending to the level of the fifth thoracic vertebra (see Figs. 1, 2).

\section{TREATMENT}

Patient was admitted to the department of neurosurgery. A ruptured intracranial aneurysm was excluded as a reason for the subarachnoidal hemorrhage by further computer tomography and magnetic resonance angiography examination. After the stabilization of the coagulopathy with activated prothrombine factors (4000 IE PPSB), left sidelaminectomy of the $12^{\text {th }}$ thoracic and the $1^{\text {st }}$ lumbar vertebra and haematoma extraction were performed (see Figs. 4-6). The procedure took 3 hours, with an intraoperative blood loss of $200 \mathrm{ml}$. The surgery was effective as the neurologic deficits were regredient. A spinal vascular malformation was excluded by magnetic resonance angiography after the surgery, but a conventional digital subtraction angiography of the spinal cord will further be necessary. One week after the surgery, the patient suffered from loss of consciousness and changes of the mental status. Image examination of the cerebrum revealed ischemic areas in both occipital lobes, probably due to cerebrovascular spasms.

\section{CONCLUSION}

Bleeding complications in cases of patients under anticoagulant medications treatment are well described in
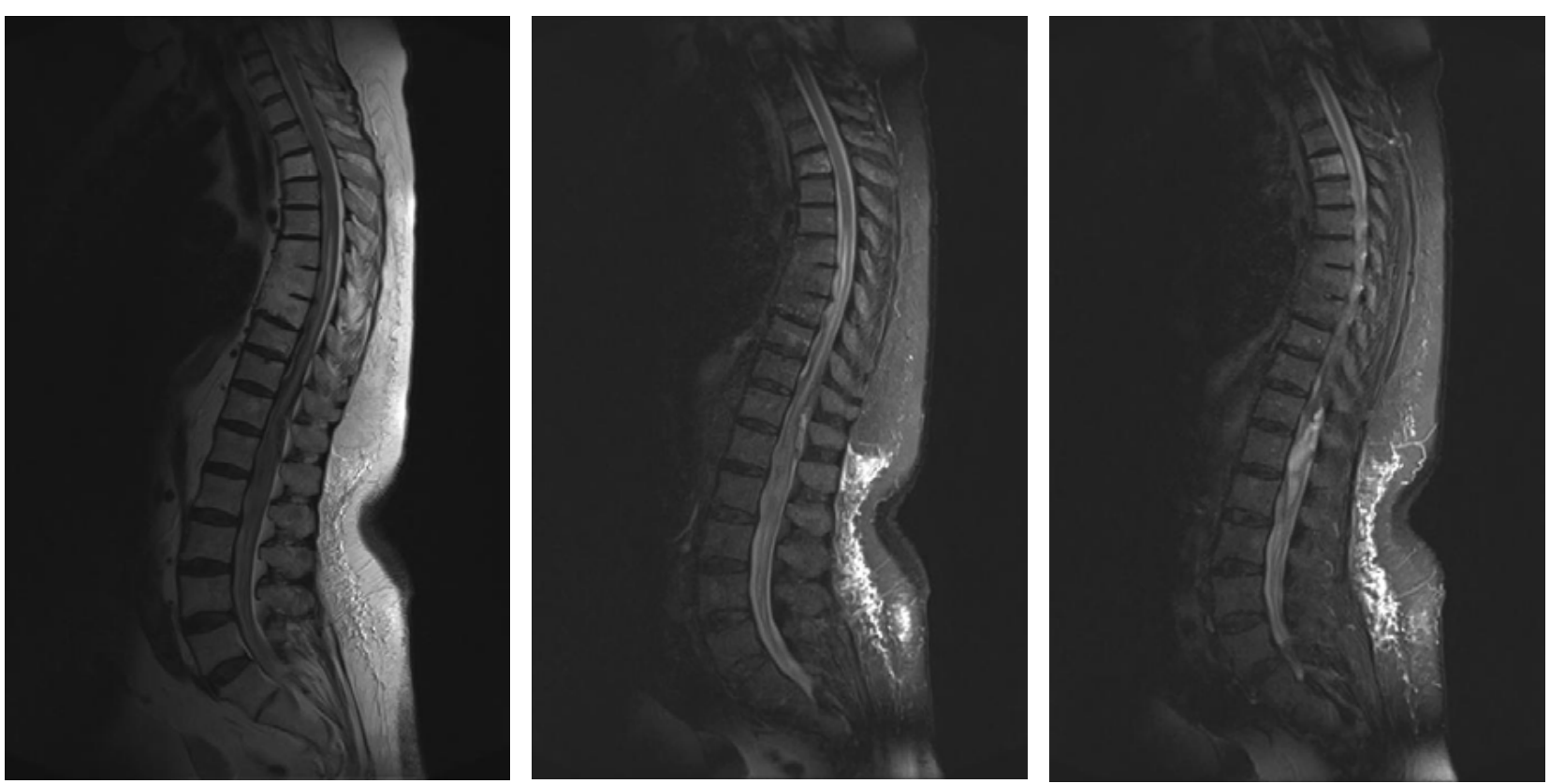

Fig. (1). Magnetic resonance tomography examination, presenting from left to right: T1-sequence median sagittal, T2- sequence median sagittal and paramedian sagittal layers. High signal intensity is visible at the level of the $12^{\text {th }}$ thoracic and the $1^{\text {st }}$ lumbar vertebra, surrounded by diffuse edema extending cranial and caudal.
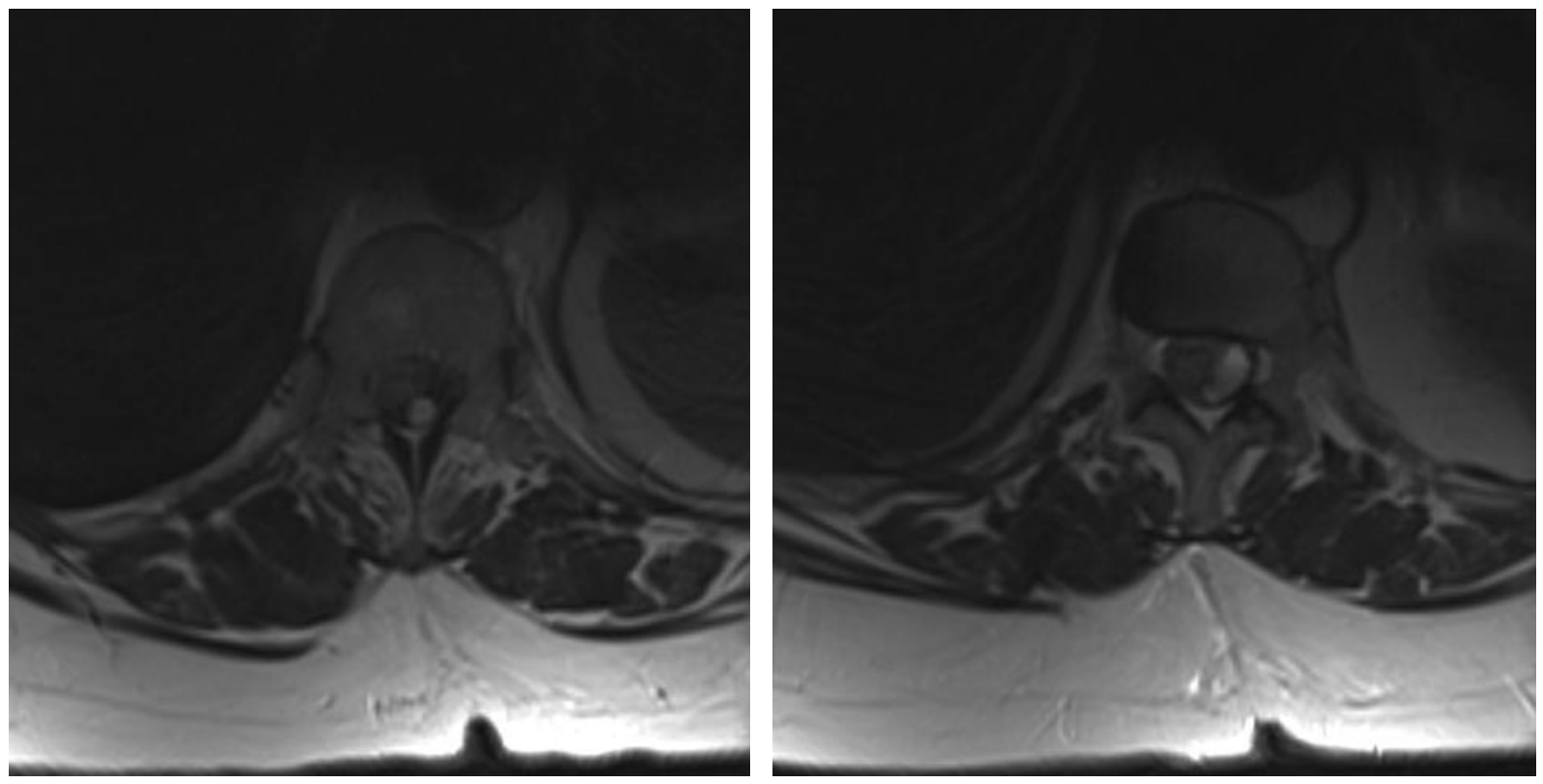

Fig. (2). Magnetic resonance tomography: Axial layer in T2- sequence, presenting the high signal intensity of the intradural haematoma at the levels of the $12^{\text {th }}$ thoracic and the $1^{\text {st }}$ lumbar vertebra. 

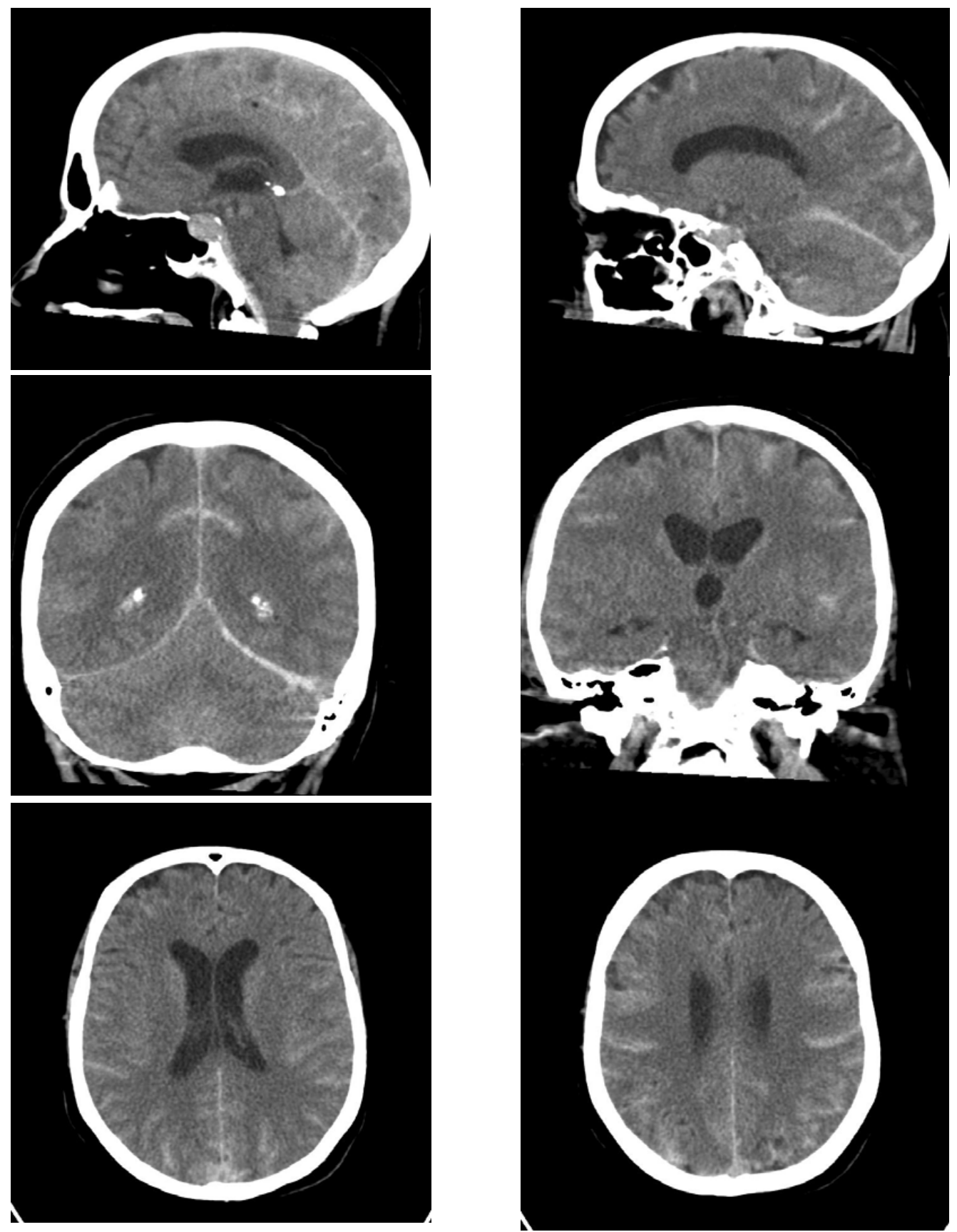

Fig. (3). Cranial computer tomography, presenting a diffuse subarachnoidal haemorrhage.

literature [1-9], but spontaneous bleeding imitating a radicular symptomatology is rare. We presented a case of sciatica and paraparesis with undulating symptomatology due to a subarachnoidal haematoma as an interesting differential diagnosis, which orthopaedic surgeons, doctors in emergency departments or even practitioners should be aware of when examining patients under anticoagulant medications treatment. A similar case was described by Penas in a female patient, presenting neck pain and weakness in both legs under anticoagulant medication, suffering from an intradural spinal and cerebral subarachnoid haemorrhage [10]. In our case, the patient presented initial sciatica, mimicking radicular involvement with a rapid progress of symptoms. In contrast to Penas` report, we present a delayed complication- cerebral ischemia due to a vasospastic reaction. Because of the chronology of symptoms, lack of a pathologic finding in the cranial CT- angiography and the presence of a fresh intradural haematoma at the lumbar level, we conclude that the cerebral, subarachnoidal haemorrhage resulted from liquor transport of blood from the lumbar area intracranially. The cranial subarachnoidal hemorrhage was also the reason for vasospastic reaction after successful surgical removal of the spinal hemorrhage. Such vasospastic reactions are also described in literature after subarachnoidal bleeding [11-14]. 


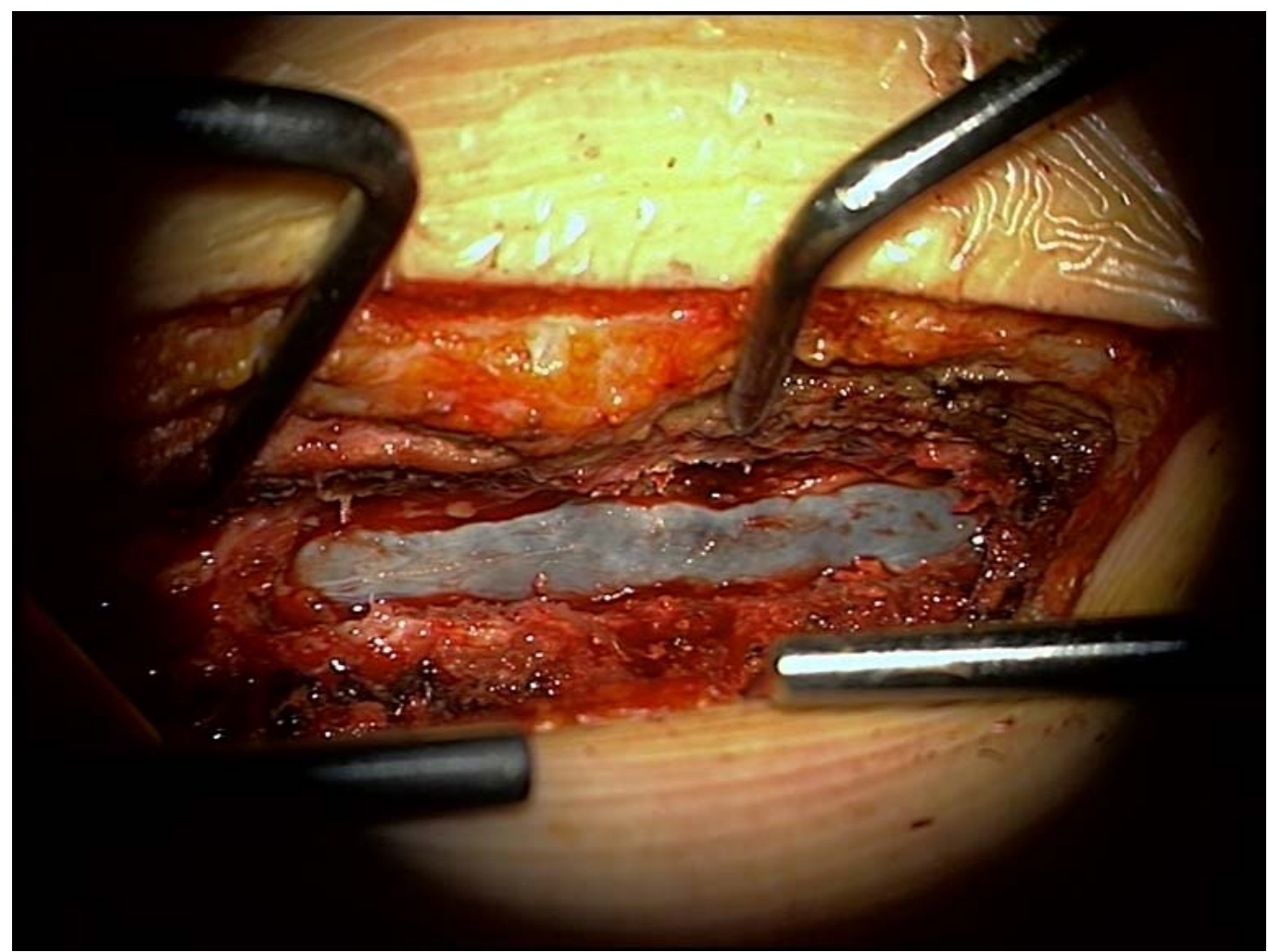

Fig. (4). Situs after Hemilaminectomy Th12 and L1 from the left side. The intradural haematoma is visible under the translucent dura mater, which is under tension.

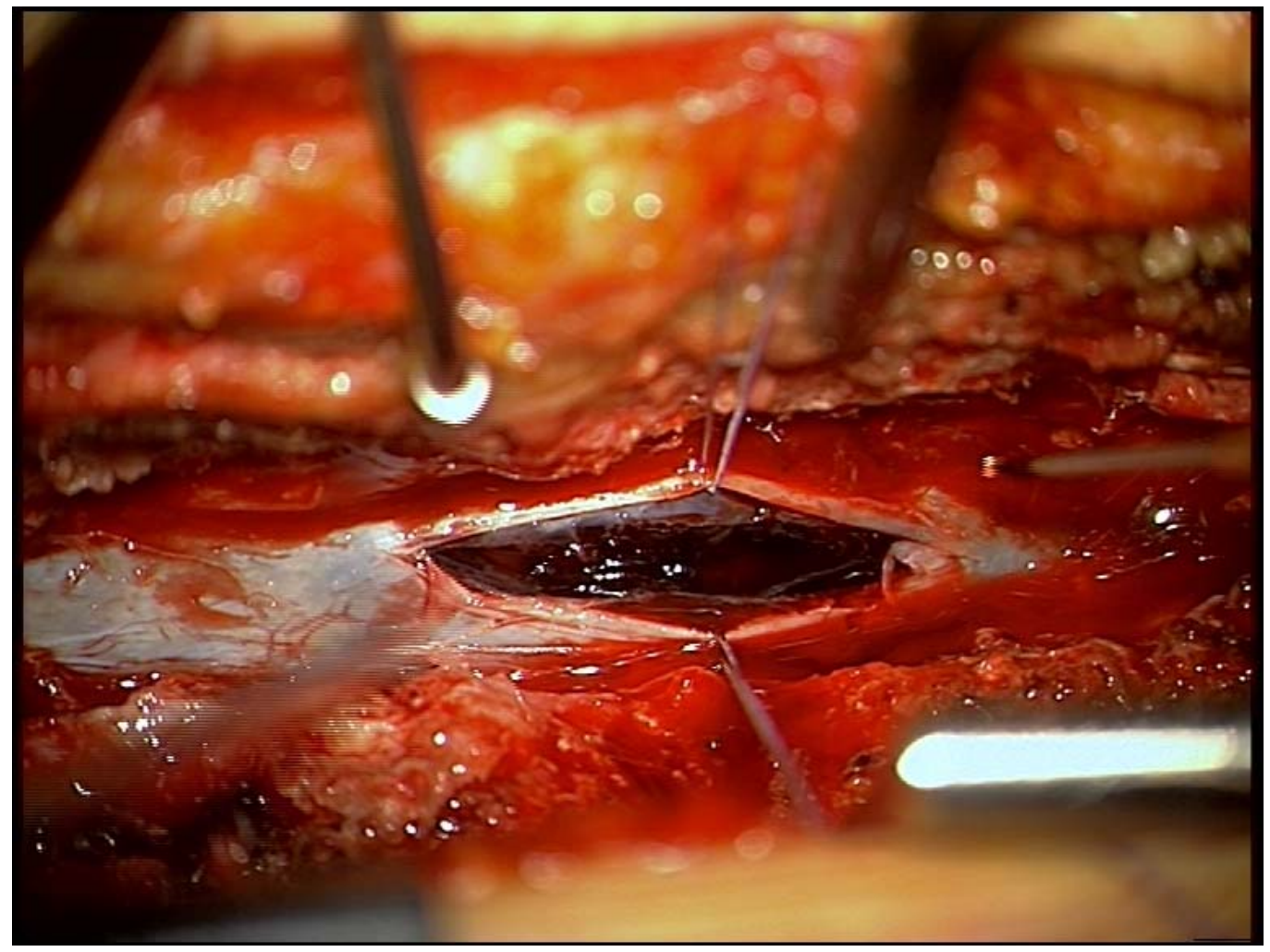

Fig. (5). Situs after discision of the dural sac, presenting the haematoma.

\section{KEY MESSAGES AND DISCUSSION}

Sciatica, with or without neurological deficits can be an alarming symptom of a spinal haemorrhage in patients under anticoagulant medication and should implicate further investigation by magnetic resonance imaging. This case further underscores the necessity of an appropriate laboratory monitoring of patients under anticoagulant medications treatment. A more frequent laboratory monitoring could 


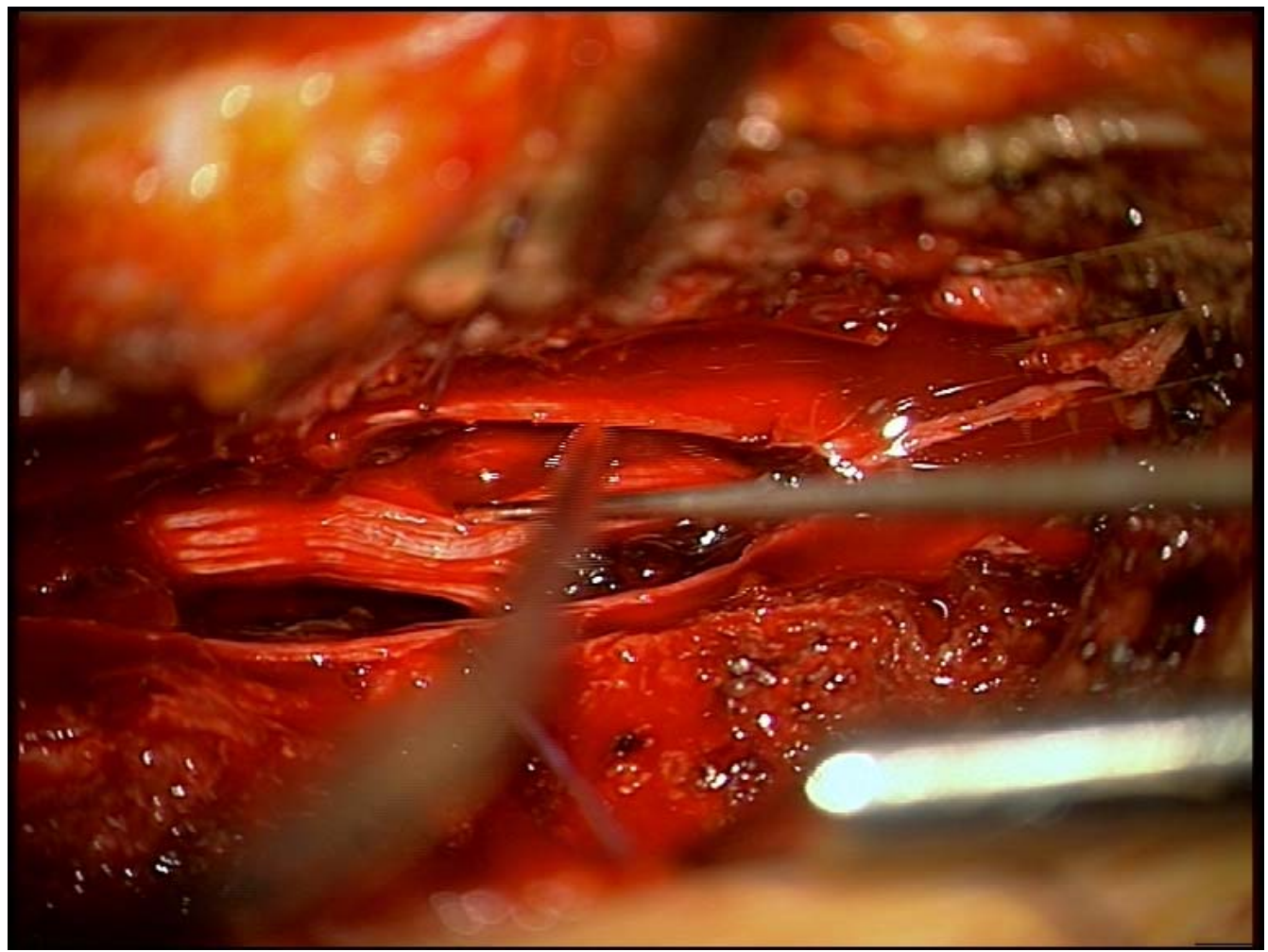

Fig. (6). Situs after extended discision of the dural sack and extraction of the haematoma, which was adherent to the roots of cauda equina.

probably avoid such complications, especially in elderly patients. Urgent surgical therapy is recommended in cases of progressive neurological deficits in patients with subarachnoidal hemorrhage of the spinal cord, even in case of coagulopathy due to cumarine medication. A detailed screening for the exclusion of vascular malformations (either cerebral or spinal) is necessary. One should be aware of delayed complications due to cerebral vasospasms, malabsorptive hydrocephalus and syringomyelia.

\section{ACKNOWLEDGEMENT}

Declared none.

\section{CONFLICT OF INTEREST}

Declared none.

\section{REFERENCES}

[1] Bernsen RA, Hoogenraad TU. A spinal haematoma occurring in the subarachnoid as well as in the subdural space in a patient treated with anticoagulants. Clin Neurol Neurosurg 1992; 94(1): 35-7.

[2] Cakirer S, Basak M, Galip GM. Cervical hematomyelia secondary to oral anticoagulant therapy: case report. Neuroradiology 2001; 43(12): 1087-8.

[3] Cihangiroglu M, Bulut S, Nayak S. Spinal subarachnoid hemorrhage complicating oral anticoagulant therapy. Eur J Radiol 2001; 39(3): 1769.
[4] Constantini S, Ashkenazi E, Shoshan Y, Israel Z, Umansky F. Thoracic hematomyelia secondary to coumadin anticoagulant therapy: a case report. Eur Neurol 1992; 32(2): 109-11.

[5] Lederle FA, Cundy KV, Farinha P, McCormick DP. Spinal epidural hematoma associated with warfarin therapy. Am J Med 1996; 100(2): 237-8.

[6] Maingi M, Glynn MF, Scully HE, Graham AF, Floras JS. Spontaneous spinal epidural hematoma in a patient with a mechanical aortic valve taking warfarin. Can J Cardiol 1995; 11(5): 429-32.

[7] Prasad SS, O'Malley M, Machani B, Shackleford IM. A case report of a spinal epidural haematoma associated with warfarin therapy. Ann R Coll Surg Engl 2003; 85(4): 277-8

[8] Robbins M, Verghese J. Acute painless progressive quadriplegia associated with warfarin use. J Am Geriatr Soc 2007; 55(5): 799-800.

[9] Vayá A, Resurección M, Ricart JM, et al. Spontaneous cervical epidural hematoma associated with oral anticoagulant therapy. Clin Appl Thromb Hemost 2001; 7(2): 166-8.

[10] Penas ML, Guerrero AL, Rodriquez Velasco M, Herrero S. Spontaneous intradural spinal haematoma associated with a cerebral subarachnoid haemorrhage. Neurologia 2011; 26(3): 182-4.

[11] Alksne JF, Branson PJ. Pathogenesis of cerebral vasospasm. Neurol Res 1980; 2(3-4): 273-82.

[12] De Salles AA. Cerebral vasospasm. Arq Neuropsiquiatr 1987; 45(3): 329-38.

[13] Weir B. The pathophysiology of cerebral vasospasm. Br J Neurosurg 1995; 9(3): 375-90.

[14] Weir B, Macdonald RL, Stoodley M. Etiology of cerebral vasospasm. Acta Neurochir Suppl 1999; 72: 27-46. 